\title{
A EMIGRAÇÃO BRASILEIRA PARA OS EUA: TIPOLOGIA E DESAFIOS
}

\author{
Roberto Marinucci*
}

\begin{abstract}
Resumo
Nos últimos anos, a despeito de uma longa tradição imigratória, o Brasil tornou-se um país de evasão populacional. A meta preferida do emigrante é os EUA, terra onde centenas de milhares de brasileiros e brasileiras tentam aproveitar das oportunidades de trabalho e realizar seus sonhos. No entanto, a vida nos Estados Unidos, longe de ser um paraíso, caracteriza-se pela luta cotidiana e sofrida em busca da plena cidadania, a saber, o direito de se sentir e ser tratado como ser humano.
\end{abstract}

Palavras-chave: Migração Internacional; Brasileiros no Exterior; EUA; Cidadania;

\section{Introdução}

$\mathrm{O}$ aumento do número de migrantes internacionais não representa uma anomalia no contexto da assim chamada globalização, caracterizada, entre outras coisas, pela crescente interconexão e interdependência entre os mercados e os povos, bem como pelo expressivo aperfeiçoamento e barateamento dos meios de comunicação e transporte. Em nível internacional, de acordo com o World Migration Report - 2005 da Organização Internacional para as Migrações (OIM), o número de migrantes internacionais, em 2005, deve ficar entre 185 e 192 milhões. ${ }^{1}$

Entretanto, o caso do Brasil não deixa de ser uma situação inédita, principalmente levando em conta que a história desse país foi moldada pela maciça imigração de povos de vários continentes. O que chama a atenção é a atual desproporção entre o número de imigrantes e emigrantes. De acordo com os dados do Censo 2000, os estrangeiros residentes no país são 733 mil, aos quais devem ser acrescentados os que vivem em situação irregular. Por outro lado, estimativas do Itamaraty apontam para a presença no exterior de, pelo menos, 1,8 milhões de brasileiros, sendo que este número refere-se exclusivamente àqueles que entraram

\footnotetext{
${ }^{*}$ Mestre em Teologia, pesquisador do Centro Scalabriniano de Estudos Migratórios (CSEM) de Brasília.

${ }^{1}$ IOM. World Migration Report - 2005. Costs and benefits of international migration. Vol. 3, p. 379. Disponível em: http://www.iom.int. Acesso em: 20 de agosto de 2005.
} 
voluntariamente em contato com consulados e embaixadas. A conclusão é evidente: o Brasil, cuja identidade se moldou pelas contribuições dos sucessivos fluxos imigratórios, transformou-se num país de evasão populacional.

$\mathrm{Na}$ primeira parte deste artigo tentaremos elucidar a tipologia da recente emigração brasileira para os Estados Unidos, apontando a época em que iniciou o fluxo migratório e os principais dados estatísticos sobre o número, os lugares de origem e de chegada dos emigrantes. $\mathrm{Na}$ segunda parte ilustraremos algumas das características gerais da presença brasileira no país norte-americano, destacando quatro aspectos: a migração irregular, o índole econômico dos projetos migratórios, as redes sociais e, concluindo, as lutas políticas em busca da plena cidadania.

\section{Tipologia da emigração brasileira para os EUA}

Um primeiro aspecto a ser abordado refere-se à origem temporal do fluxo migratório para os EUA. Trata-se de uma questão extremamente significativa por duas razões: permite diagnosticar as possíveis causas do fenômeno e, ao mesmo tempo, verificar a existência e, eventualmente, analisar as características da segunda ou terceira geração de emigrantes. ${ }^{2}$

Segundo Teresa Sales, foi a partir da segunda metade dos anos 80 que se desencadearam os fluxos maciços da emigração brasileira para o exterior e, principalmente, para os EUA. ${ }^{3} \mathrm{O}$ próprio Censo dos EUA de 2000 evidencia, com muita clareza, o sensível aumento da presença brasileira no território, como atesta o World Migration Report - 2005 da IOM:

Like its northern neighbour, Brazil is also witnessing an emigration trend. The US has become one select destination, as legal and irregular immigrants make homes in states such as Florida, Massachusetts and New York. Inflows of Brazilian immigrants into the US have risen steadily since 1999, from slightly less than 4,000 to nearly 9,500 in 2002. According to US Census figures, the stock of Brazilians, too, has

\footnotetext{
${ }^{2}$ No caso dos brasileiros, só recentemente apareceram estudos que objetivam analisar a situação da segunda geração de brasileiros nos EUA. Cf. SALES, Teresa e LOUREIRO, Márcia. Imigrantes brasileiros adolescentes e de segunda geração em Massachusetts, EUA. In: Revista Brasileira de Estudos de População. Campinas, v. 21, n. 2, (jul./dez. 2004) 217-239; SALES, Teresa. Segunda geração de emigrantes brasileiros nos EUA. In: In: CNPD (org.), Migrações internacionais - contribuições para políticas, p. 361-374.

${ }^{3}$ SALES, Teresa. Brasileiros longe de casa, p. 20-21.
} 
been rising from 82,500 in 1995 to 212,400 in 2000. (Note that the inflow numbers do not capture unauthorized entries). ${ }^{4}$

Essas afirmações confirmam o World Economic and Social Survey - 2004 da ONU, de acordo com o qual, desde o primeiro qüinqüênio dos anos 80, o Brasil começa a ter saldos migratórios constantemente negativos, sendo, por isso, classificado atualmente como "country of emigration". 5

No que se refere à distribuição dos brasileiros residentes no exterior, estimativas de 2002 relativas a informações disponibilizadas por embaixadas e consulados, apontam os EUA como o principal pólo de atração, com cerca de 800 mil pessoas, seguido pelo Paraguai e o Japão. A preferência pelo país norte-americano liga o Brasil aos demais países da América Latina: não é por acaso que cerca de $75 \%$ dos emigrantes desta região residem nos EUA. ${ }^{6}$

A imprensa nacional e internacional, nos últimos meses, tem também sublinhado o expressivo aumento das detenções de brasileiros na fronteira entre México e EUA, o que pode ser interpretado como um indicador de um recente acirramento da emigração para o país norteamericano. Trata-se de um verdadeiro boom, pois a porcentagem de brasileiros presos, de outubro de 2004 até abril de 2005, decuplicou em relação a $2000 .^{7}$

Além disso, existem outros fatores que, direta ou indiretamente, confirmam o crescimento da emigração para os EUA. Antes de tudo, houve também um aumento das detenções em território mexicano, de forma tal que o governo local acabou de exigir novamente o visto para a entrada de brasileiros no país. ${ }^{8}$ Ao mesmo tempo, nos EUA, denota-se o crescimento de posturas mais rígidas em relação aos brasileiros, tanto daqueles que estão tentando entrar, quanto daqueles

\footnotetext{
${ }^{4}$ IOM, op. cit., p. 93.

${ }^{5}$ ONU - DEPARTMENT OF ECONOMIC AND SOCIAL AFFAIRS. World Economic and Social Survey - 2004, p. 36. Disponível em : http://www.un.org/esa/analysis/wess/ Acesso em: 10 de agosto de 2005.

${ }^{6}$ Cf. COMISIÓN ECONÓMICA PARA AMÉRICA LATINA Y EL CARIBE. Panorama Social de América Latina 2004, p. 40-41. Disponível em http://www.eclac.cl Acesso em: 10 de agosto de 2005. De acordo com o relatório, residem nos EUA cerca de 15 milhões de pessoas nascidas na América Latina.

${ }^{7} \mathrm{Na}$ opinião de alguns analistas, o aumento do número de presos nos EUA deveria ser interpretado a partir de uma nova estratégia adotada pelos atravessadores que, explorando uma brecha da legislação, entregam os emigrantes brasileiros para a Patrulha de Fronteira: por não serem mexicanos, eles têm direito a um julgamento e, portanto, são libertados e notificados para comparecer a uma audiência judicial. Na maioria dos casos, os emigrantes não se apresentam, permanecendo, assim, de forma administrativamente irregular no país. Esta estratégia evita os riscos da travessia de rios e desertos, bem como de outras formas de violência física e psicológica.

${ }^{8}$ Cf. México vai exigir vistos de brasileiros. Disponível em: http://noticias.uol.com.br/ultnot/reuters/2005/09/08/ult729u50133.jhtm. Acesso em: 08 de setembro de 2005.
} 
que vivem de forma irregular no país. As cada vez mais freqüentes deportações por meio de vôos fretados são um claro sintoma dessa situação.

Em suma, no início do terceiro milênio constata-se um acirramento da emigração brasileira para os EUA, emigração que se configura cada vez mais como "irregular". ${ }^{9}$ É esta a condição de cerca de 10 a $15 \%$ da totalidade dos migrantes internacionais. Nos Estados Unidos, de acordo com a OIT, as pessoas residentes de forma irregular são estimadas entre 7 e 8 milhões, em 2000. O Governo norte-americano acredita que cerca de 700 mil pessoas entram irregularmente no país, a cada ano. Quanto aos brasileiros não há estatísticas confiáveis, mas levando-se em conta o grande número de prisões na fronteira entre EUA e México, pode-se conjeturar que o número seja significativo. ${ }^{10}$

No que se refere ao perfil dos brasileiros e brasileiras que emigram para os EUA não há unanimidade. Acredita-se, no entanto, que boa parte deles seja de classe média ou média-baixa, provindos sobretudo das regiões Sudeste e Sul, com destaque pelo Estado de Minas Gerais.

Uma pesquisa realizada por Teresa Sales e Márcia Loureiro ${ }^{11}$ com brasileiros adolescentes e de segunda geração no Estado de Massachusetts - EUA, revela que, dentre as mães brasileiras que tiveram filhos na região entre 1999 e 2001, a maioria provinha do Estado de Minas Gerais (39,98\%), seguido por São Paulo (12\%), Paraná (9\%), Rio de Janeiro (9\%) e Santa Catarina (7\%). Além de confirmar a hegemonia mineira e, mais em geral, das regiões Sul e Sudeste, a pesquisa revelou mais um dado interessante: 24 das 27 Unidades da Federação brasileiras comparecem na lista, o que, na opinião das pesquisadoras, aponta para uma expansão das áreas de origem da emigração para os EUA. ${ }^{12}$

Apesar das limitações geográficas - estado de Massachusetts - a pesquisa confirma a existência de focos emigratórios em determinadas regiões do Brasil - possivelmente relacionados

\footnotetext{
${ }^{9}$ A expressão "pessoa em situação irregular" é hoje freqüentemente apontada como a mais "politicamente correta" por não estar relacionada diretamente com a idéia de delinquiência (como no caso de "ilegal" ou "clandestino") e por ser mais completa e abrangente do que o termo "indocumentado" (cf. OIT. En busca de un compromiso equitativo para los trabajadores migrantes en la economía globalizada, n. 36).

${ }^{10}$ Os dados oficiais do Office of Policy and Planning U.S. - Immigration and Naturalization Service, estimam em 77 mil o número de brasileiros presentes irregularmente nos EUA, em 2000, um número bem superior aos 20 mil de 1990. O Brasil, de acordo com essas estatísticas, registra uma das mais altas porcentagens de crescimento. Cf. http://uscis.gov/graphics/shared/aboutus/statistics/Ill Report 1211.pdf. Acesso em: 01 de setembro de 2005.

${ }^{11}$ Cf. SALES e LOUREIRO, op. cit., p. 217-239.

${ }^{12}$ Outra pesquisa realizada pelas estudiosas com 118 adolescentes da área metropolitana de Boston aponta para uma presença expressiva também da região centro-oeste (cf. SALES e LOUREIRO, op. cit., p. 227).
} 
às redes sociais - mas, ao mesmo tempo, aponta para uma possível e progressiva generalização das áreas de origem da emigração.

Quato ao lugar de destino nos Estados Unidos, registra-se uma clara concentração de brasileiros e brasileiras em determinadas regiões - Boston, Miami, Nova Iorque, Los Angeles coincidentes, em muitos casos, com a presença consular - Nova Iorque, Boston, Miami, Los Angeles, São Francisco, Washington, Chicago e Houston.

Embora se trate de uma emigração tradicionalmente urbana ou metropolitana, foi recentemente relatada uma tendência à descentralização da presença brasileira. Uma pesquisa realizada no estado de Massachusetts por Tiago Jansen (a partir de 8.623 formulários de preenchimento para a aquisição de passaportes do Consulado do Brasil em Boston), aponta a presença de brasileiros e brasileiras em 250 das 351 cidades do estado. De acordo com o pesquisador, esta interiorização das comunidades brasileiras se deve tanto a brasileiros recémchegados quanto ao deslocamento dos mais antigos. ${ }^{13}$ À mesma conclusão chega a já citada pesquisa de Sales e Loureiro em relação ao nascimento de filhos de brasileiras naquela região. ${ }^{14}$

Outras pistas para a análise da distribuição da presença brasileira nos EUA podem ser encontradas no Yearbook of Immigration Statistics do Office of Immigration Statistics dos EUA. ${ }^{15} \mathrm{O}$ limite desses dados está no fato de considerar apenas a imigração permanente regular (legal permanent residence), que, no caso dos brasileiros, corresponde a cerca de 5 mil unidades por ano - nos anos 90 - e de cerca de 9 mil no começo do terceiro milênio. Mesmo assim há alguns dados significativos, sobretudo em se considerando as dinâmicas das redes sociais e da reunificação familiar.

Assim, de acordo o Yearbook of Immigration Statistics, de 2001 até 2004, os estados de New Jersey, Nova Iorque, Massachusetts, Flórida e Califórnia concentraram cerca de 2/3 dos brasileiros, embora houve uma leve diminuição dessa concentração, passando-se de 69,2\% em 2001, para 67,4\% em 2004. Fora dessas áreas tradicionais de emigração, as estatísticas apontam para um aumento expressivo da presença de brasileiros nos estados do Texas (divisa com o México), Illinois (sobretudo na cidade de Chicago) e New Hampshire (Estado que faz divisa com

\footnotetext{
${ }^{13}$ Cf. "Comunidades se descentralizam e vão ao interior". Folha de São Paulo, Caderno Mundo, 21 de março de 2005.

${ }^{14}$ Cf. SALES e LOUREIRO, op. cit., p. 226.

${ }^{15}$ Disponível em: http://uscis.gov/graphics/shared/statistics/yearbook/index.htm. Acesso em: 25 de agosto de 2005.
} 
Massachusetts). Numa análise mais geral, percebe-se que praticamente todos os estados do país norte-americano acolhem brasileiros.

Apesar das diversidades, as pesquisas e estatísticas supracitadas confirmam, por um lado, a concentração e, ao mesmo tempo, sugerem uma incipiente descentralização. Todos esses dados, no entanto, não esclarecem se à suposta dispersão dos brasileiros corresponde também um enfraquecimento das relações comunitárias e inter-étnicas. Em outros termos, a descentralização deve ser interpretada como sintoma de maior individualização dos brasileiros e, quem sabe, de um aprofundamento dos processos de integração ou assimilação dos mesmos ou, então, estaríamos diante de deslocamentos de pequenos grupos que, em pequenas cidades, continuam priorizando suas relações étnicas?

Resumindo, podemos inferir, a partir dos dados até aqui apresentados, que o fluxo migratório brasileiro para os EUA tem seu foco a partir da segunda metade dos anos 80, com um acirramento nos primeiros anos do novo milênio. Embora em número reduzido, começa a tomar forma a segunda geração de migrantes. A maioria dos brasileiros residentes nos EUA provém das regiões Sudeste e Sul, com destaque por Minas Gerais, embora haja indícios de uma progressiva dilatação dos lugares de origem. Algo análogo ocorre em relação aos estados de destino, sendo que a uma inicial concentração em determinadas regiões metropolitanas corresponde uma recente - suposta - descentralização.

\section{Alguns traços característicos da emigração brasileira para os Estados Unidos}

Mesmo levando em conta a heterogeneidade do perfil dos brasileiros e brasileiras que emigram para os EUA, podemos, nesta parte, tentar traçar algumas características que, em muitos casos, são compartilhadas pela maioria deles.

\subsection{Emigração (freqüentemente) irregular}

Nos últimos anos, verificou-se uma tendência mundial em endurecer as políticas imigratórias, sobretudo nos países do Norte do mundo, a saber, os economicamente mais ricos. Essa tendência foi exacerbada pela suposta luta contra o terrorismo desencadeada a partir dos acontecimentos do dia 11 de setembro de 2001. De fato, práticas de contenção da migração internacional estão se tornando cada vez mais comuns, como a redução do número de vistos concedidos, a deportação de migrantes irregulares, a detenção em aeroportos de passageiros 
estrangeiros em trânsito, a partilha entre países de bancos de dados sobre migrantes, o controle mais rígido das fronteiras por meio de sofisticados instrumentos tecnológicos (satélites) ou simples muros.

Há, no entanto, uma evidente contradição entre o fechamento das fronteiras e a insistente procura por trabalhadores qualificados e não-qualificados, principalmente daqueles que podem oferecer horários flexíveis e disponibilidade em assumir trabalhos mal remunerados e recusados pelos autóctones. Saskia Sassen chama isso de "duplo regime de circulação" "16. Com efeito, o capital financeiro e as mercadorias gozam de mais liberdade de ir e vir do que os próprios trabalhadores migrantes.

Essas rápidas reflexões visam evidenciar como a simultaneidade entre o enrijecimento das políticas imigratórias e a procura por mão-de-obra barata - provocada freqüentemente pelo envelhecimento da população autóctone - de fato, estimula a entrada ou a permanência irregular de migrantes, bem como a formação de "agências de viagem" ilegais. Ao que tudo indica, muitos dos brasileiros que residem nos EUA entram ou permanecem no país de forma irregular, assim como atestam as supracitadas estatísticas das detenções na fronteira México-EUA e os dados oficiais do governo estadunidense.

A residência irregular nos EUA acarreta um conjunto de conseqüências que prejudicam gravemente o processo integrativo e o equilíbrio psicossocial dos migrantes. Entre outras, cabe ressaltar a extrema dificuldade em ter acesso ao sistema sanitário, à educação universitária, à carteira de motorista e ao trabalho com carteira assinada. O principal empecilho está na obtenção da Social Security Card que é freqüentemente falsificada e vendida aos emigrantes por quadrilhas. Enfim, por medo de serem descobertos e expulsos, muitas vezes, os migrantes sequer utilizam os serviços aos quais têm direito, embora, com seus trabalhos, contribuam ao enriquecimento do país em que vivem.

Outros fatores de vulnerabilidade são a extorsão, os abusos e a exploração por parte de empregadores, burocratas corrompidos e, principalmente, agentes de migração que, não raramente, cobram cerca de 10 mil dólares para a viagem e a entrada nos EUA. Este dinheiro deve ser pago pelos migrantes num prazo extremamente curto, pois se cobram juros em dólares e, sobretudo, se ameaçam os familiares no Brasil. Há inclusive o risco que os próprios parentes tenham determinados bens confiscados caso não ocorra ou demore o pagamento da dívida.

\footnotetext{
${ }^{16}$ Cf. SASSEN, Saskia. Globalizzati e scontenti. Il destino delle minoranze nel nuovo ordine mondiale, p. 38-40
} 
Em suma, os brasileiros que residem nos EUA em situação irregular vivem uma condição de extrema vulnerabilidade, análoga - não idêntica - àquela em que se encontram os solicitantes de refúgio nos países de origem. Com efeito, os refugiados fugiram da própria terra por temores fundados de serem perseguidos e perderem a própria vida. Já os brasileiros que migraram e/ou residem de forma irregular nos EUA vivem com temores fundados de serem perseguidos e perder "aquela vida", ou seja, a vida que eles estão construindo na América do Norte, enfrentando todo tipo de dificuldade. Para esses migrantes, "aquela vida" é tão importante que por ela desafiaram a travessia da fronteira com o México, inclusive correndo o risco de morte. Para muitos, é "uma vida" pela qual vale a pena morrer.

\subsection{Emigração de trabalho}

Um segundo aspecto a ser enfatizado da emigração brasileira para os EUA é a finalidade claramente "econômica". Várias pesquisas realizadas em diferentes lugares, tanto no Brasil quanto nos EUA, convergem sobre esse aspecto.

De acordo com Fusco ${ }^{17}$ (que analisa os resultados de uma pesquisa em Governador Valadares - MG com pessoas que tiveram experiência de migração internacional), $80 \%$ dos que se deslocaram para os EUA tiveram como motivação a "procura de trabalho", sendo que essa porcentagem sobe para $88 \%$ entre os homens. A "reunificação familiar" tem uma porcentagem relevante apenas entre as mulheres, perfazendo $22,6 \%$ do total das entrevistadas. Quanto ao tipo de emprego, a ocupação "de entrada" mais comum para os migrantes valadarenses é o "trabalho doméstico", seguido pelo "lavador de pratos" e "pedreiro". Em geral, a maioria dos migrantes encontrou sua primeira ocupação no setor terciário (75\%), a saber, na prestação de serviços e comércio de mercadorias.

Segundo Fusco, os valadarenses, pelo menos nos primeiros tempos, são obrigados a aceitarem empregos de baixa qualificação, às vezes sacrificando o status ocupacional que tinham no Brasil em troca de salários maiores. ${ }^{18}$ Freqüentemente, a vida nos Estados Unidos, desde o início, é caracterizada por uma busca exasperada de dinheiro, a fim de saldar as dívidas com os

\footnotetext{
${ }^{17}$ Cf. FUSCO, Wilson. Redes sociais nas migrações entre Governador Valadares e os Estados Unidos. In: CNPD (org.), Migrações internacionais - contribuições para políticas, p. 431-432.

${ }^{18}$ A precariedade do trabalho é atestada pelo elevado número de acidentes de trabalho, não raramente fatais, que muitos brasileiros sofrem, sobretudo na área da construção civil (por exemplo: "Sepultado catarinense que morreu em acidente nos EUA" In: Brazilian Times, 20 de junho de 2005; "Americano ajuda brasileiro que perdeu a perna em acidente de trabalho" In: Brasilian Times, 29 de junho de 2005).
} 
atravessadores, parentes e/ou amigos; enviar remessas para os familiares que ficaram no Brasil; depositar dinheiro na própria conta no país de origem a fim de garantir o próprio retorno; permitir uma vida digna nos EUA. O drama da vida de muitos migrantes pode ser bem resumido por um trecho do relatório da viagem pastoral de Pe. Eduardo Alencar Lustosa na Califórnia:

Todos estão lá devido à questão econômica, uma minoria dos jovens foi estudar. Muitos perderam tudo, faliram. O processo de saída do Brasil até a entrada na América é uma verdadeira Via Sacra. Muitos tentam entrar pelo México, onde enfrentam prisões e têm que pagar muitos dólares para os atravessadores e a imigração. Chegando lá, iniciam uma outra Via Sacra, com relação à moradia, emprego, língua e a SAUDADE. Muitos deixam no Brasil a esposa ou o esposo, filhos e pais. Estive com um casal muito jovem, que havia chegado há 6 meses. Deixaram com os pais um bebê (...) e outro filho de 1 ano e meio... Até quando? Só Deus sabe. Por isso se submetem a todo tipo de serviço: faxina, babá, construção civil, entrega de jornal e pizza, etc., de domingo a domingo, várias horas por dia (...). ${ }^{19}$

O móvel econômico da emigração brasileira para os EUA é confirmado por Sales e Loureiro $^{20}$ que, ao entrevistarem 45 jovens adolescentes brasileiros numa high school em Massachusetts, descobriram que 55\% deles trabalham regularmente, ao passo que $22 \%$ trabalham no final de semana ou já trabalharam e estão disponíveis a aceitarem novos empregos. Os que não tinham experiências laborais estavam incluído na faixa mais jovens do grupo entrevistado, a saber, entre 13 e 14 anos. Os jovens brasileiros referiram trabalhar até 6/8 horas por dia, mostrando inclusive a dificuldade em conciliar trabalho e estudo, principalmente quando o empregador exige flexibilidade nos horários.

Assim, diferentemente que no Brasil, a vida desses jovens nos EUA é caracterizada pela experiência do trabalho, assumido a fim de ajudar os pais ou para ter acesso a determinadas formas de consumo. Seja como for, há sempre o risco que a valorização do trabalho, por parte tanto dos adolescentes jovens quanto de seus pais, prejudique o interesse e o compromisso pelos estudos, condição freqüentemente necessária para o futuro acesso a empregos melhor remunerados.

Finalmente, há outro elemento que pode ser citado a fim de ressaltar a dimensão econômica da emigração brasileira: as remessas enviadas para o Brasil. Os dados gerais do BID

\footnotetext{
${ }^{19}$ Relatório da Missão de Pe. Eduardo Alencar Lustosa com os brasileiros e brasileiras imigrados na Califórnia USA. In: Boletim Além Fronteiras Ano II, n. 6 (abril-junho 2001) 5.

${ }^{20}$ Cf. SALES e LOUREIRO, op. cit., p. 228-231.
} 
falam em 5,6 bilhões de dólares que os brasileiros no exterior enviaram, em 2004, à própria pátria, quantia inferior apenas, na América Latina, às remessas recebidas pelo México. Quanto às remessas dos EUA, acredita-se que sejam na ordem de 1,8 ou 1,9 bilhão de dólares, um número significativo, mas inferior às remessas do Japão, onde residem cerca de 250 mil brasileiros.

Como justificar essa desproporção? O dekasségui, na opinião de muitos, trabalha mais de 10 horas por dia e vive de forma extremamente austera, esperando o retorno ao Brasil. Já, nos EUA, muitos brasileiros, principalmente os que já estão com a situação regularizada, muitas vezes não desejam mais regressar, aprendem a língua, matriculam seus filhos em escolas locais, assumem o estilo de vida e as formas de consumo dos norte-americanos. No entanto, acredito que deva ser levado em conta também um outro fator: diferentemente que no Japão, muitos brasileiros entraram e residem nos EUA de forma irregular, o que significa que, geralmente, nos primeiros meses ou anos terão que trabalhar simplesmente para pagar a dívida com os atravessadores, parentes ou amigos, às vezes, já residentes nos EUA. Sem contar que a condição irregular pode dificultar inclusive o envio oficial de remessas, obrigando o migrante a buscar formas alternativas, como a entrega do dinheiro por mão própria, por mãos de parentes e amigos.

Seja como for, o aumento das remessas - confirmado inclusive pelos dados oficiais do Banco Central do Brasil - pode sinalizar tanto o aumento da presença brasileira no país, quanto a melhor qualificação dos empregos, quiçá, decorrente de um processo de integração mais avançado. Ao mesmo tempo, numa ótica sócio-antropológica, esse fenômeno aponta também para a existência de redes ou "comunidades transnacionais", ou seja, comunidades formadas por pessoas que residem em localidades diferentes, mas que mantém estritas relações econômicas, culturais e sociais. ${ }^{21}$

De todas essas considerações podemos inferir que a emigração brasileira para os EUA, tanto no que se refere ao móvel inicial, quanto à vida cotidiana no lugar de chegada de adultos e jovens, é caracterizada por uma forte índole econômica que, de fato, norteia as escolhas do dia-adia dos emigrantes.

\subsection{Emigração comunitária}

\footnotetext{
${ }^{21}$ Cf. SERRANO, Javier O. Acerca de las remesas de dinero que envían los migrantes: procesos de intercambio social em contex tos migratórios internacionales. In: Estudios Migratorios Latinoamericanos, Ano XVII, n. 51 (agosto 2003), p. 307-332.
} 
Um outro aspecto significativo da presença brasileira nos Estados Unidos é a formação das, assim chamadas, "comunidades étnicas”, ou seja, a reunificação de grupos de migrantes em determinadas cidades ou regiões do país. Apesar das recentes pesquisas supracitadas que apontam para uma incipiente descentralização das comunidades, não há dúvida de que existem áreas geográficas de concentração da migração brasileira, a saber, as cidades - e as regiões contíguas - de Boston, Nova Iorque, Miami e Los Angeles.

A razão disso pode ser facilmente encontrada na importância basilar das redes sociais para a emigração, como bem comprovado por Fusco ${ }^{22}$. De acordo com o pesquisador, apenas $20 \%$ dos emigrantes valadarenses entrevistados afirmaram não conhecer ninguém no lugar de destino nos EUA. A maioria podia contar com o apoio de parentes (56\%) ou amigos (23\%). Esses dados comprovam como "os laços sociais unem origem e destino do fluxo valadarense, além de evidenciar o parentesco como o principal componente das redes sociais daquela cidade". ${ }^{23}$ Essas redes sociais são fundamentais a fim de garantir aos migrantes o primeiro amparo para a estada no lugar e, sobretudo, as informações necessárias para o acesso ao mercado de trabalho norte-americano e outros serviços básicos. Além disso, elas possibilitam uma integração mais gradativa dos emigrantes que, desta maneira, podem contar com alguns referenciais identitários fundamentais para a própria saúde psicossocial.

O aspecto comunitário da emigração brasileira para os EUA pode ser averiguado também pela relevância das associações brasileiras, que continuam crescendo apesar das dificuldades que freqüentemente os imigrantes enfrentam para a participação constante, devido aos horários de trabalho, às disponibilidades financeiras e à distância entre a sede associativa e o domicílio. Estamos de acordo com Antonio Morell Blanch quando afirma que

El asociacionismo, de inmigrantes o de autóctonos, es fruto de una necesidad humana: la necesidad de reunirse, dialogar, intercambiar afectos, inquietudes y experiencias. Pero en el caso de los inmigrantes, cuanto menos en las primeras fases del proceso migratorio, esta necesidad se acentúa por la sensación de aislamiento y soledad que provoca enfrentarse a un entorno desconocido, que en no pocas ocasiones se percibe como hostil. $^{24}$

\footnotetext{
${ }^{22}$ FUSCO, op. cit., p. 427-446.

${ }^{23}$ Ibidem, p. 438.

${ }^{24}$ MORELL BLANCH, Antonio. El papel de las asociaciones de inmigrantes en la sociedad de acogida. In: Migraciones n. 17 (junho 2005) 113.
} 
Existem várias tipologias para classificar as associações de imigrantes. ${ }^{25}$ No nosso caso, achamos significativo levar em conta dois aspetos: os atores e as finalidades. No primeiro caso é importante avaliar se o grupo associativo é "para" ou "dos" imigrantes. Estes, em outras palavras, são os protagonistas ou os destinatários do planejamento e das atividades do grupo? Ao nosso ver, as duas formas associativas têm valor, mas, em linha de princípio, as associações para os migrantes, com o tempo, deveriam deixar o espaço para aquelas protagonizadas pelos próprios estrangeiros.

Um exemplo disso pode ser encontrado nas comunidades religiosas ligadas à Igreja Católica, como afirma o relatório final do "V Encontro da Pastoral brasileira nos EUA - 2000", ocorrido em Kearney, NJ:

Os primeiros líderes a iniciarem um serviço pastoral para as comunidades de brasileiros foram os religiosos/as e sacerdotes americanos. Muitos fizeram o esforço de aprender os costumes e a língua para facilitar a comunicação. Aumentando as necessidades, a própria Igreja americana dirigiu-se à Igreja do Brasil. Junto a eles, religiosos/as e sacerdotes brasileiros em visita ou complementando estudos no Canadá e EUA tomaram consciência da nova realidade e a levaram para seus bispos. (...) Aos poucos, as comunidades foram se estruturando e procurando respostas para a nova realidade que estavam vivendo. ${ }^{26}$

Hoje, a Pastoral dos Brasileiros no Exterior $(\mathrm{PBE})^{27}$, organismo da CNBB, envia ministros para as comunidades mais numerosas de católicos brasileiros nos EUA, promovendo, assim, a passagem de comunidades "para" a comunidades "de" brasileiros.

A dimensão religiosa é extremamente importante para a vida de muitos migrantes que encontram nela o sentido, os valores, a segurança e a força para enfrentar e superar os momentos de desânimo, crise e violência que o processo migratório pode acarretar. As associações religiosas se tornam, freqüentemente, lugares de vivência e de experiência comunitária do sagrado, conforme a peculiaridade de cada denominação religiosa. No entanto, a participação em Igrejas responde também a motivações de ordem afetiva, cultural, assistencial e, inclusive, identitária. Em outras palavras, nos EUA, essas associações tendem, geralmente, a incorporar tanto atividades especificamente religiosas, quanto práticas assistências de promoção. Pastores,

\footnotetext{
${ }^{25}$ Cf. OLIVEIRO, Fedo. L'associazionismo in emigrazione. Servizio migranti Ano XIV, n.6 (novembredicembre/2004) 431-438; MORELL BLANCH, op. cit., pp. 125-129.

${ }^{26}$ Cf. A Pastoral brasileira nos EUA. V encontro. 16-18 de outubro de 2000 - Kearny, NJ (mímeo).

${ }^{27}$ Cf. MARINUCCI, Roberto. A Pastoral dos Brasileiros no Exterior (PBE - CNBB). In: SERVIÇO PASTORAL DOS MIGRANTES (org.). Travessia na de\$ordem global. Fórum Social das Migrações, p. 253-260.
} 
padres e freiras "atuam como interpretes e tradutores em hospitais, em escolas ou perante a Justiça; ajudam a veicular informações sobre empregos e moradia disponíveis, promovem atividades para arrecadação e distribuição de alimentos e vestimentas". 28

Além da religiosa, cabe destacar também a existência de associações com finalidades "étnico-cultural", "social" e "política". Na primeira podem ser incluídas as associações que desenvolvem atividades de sensibilização e valorização da cultura brasileira objetivando fomentar um clima de diálogo intercultural e, ao mesmo tempo, garantir ao migrante um contato com referenciais identitários abandonados com a saída do próprio país. Neste grupo podem ser incluídas as atividades de divulgação de música, filmes, culinária, danças, folclore (sobretudo o Carnaval), religiões e, inclusive, esportes brasileiros.

Já as associações de cunho social abrangem aqueles segmentos que visam acompanhar e auxiliar o processo de inserção de brasileiros nos Estados Unidos, tentando responder a suas necessidades mais básicas e imediatas, como a procura de emprego e moradia, o conhecimento ou aperfeiçoamento da língua, o acesso aos serviços sanitários e educacionais, a obtenção da documentação, entre outros.

Das associações de cunho político trataremos no próximo capítulo. Por enquanto é suficiente sublinhar como a dimensão comunitária - redes sociais de parentesco ou amizades e associações de e para estrangeiros - representa um aspecto central da presença brasileira nos Estados Unidos, principalmente para os migrantes recém-chegados e para aqueles que cultivam o desejo de voltar para o Brasil. A reafirmação da própria identidade brasileira, neste caso, permite alimentar o sonho do retorno ao Brasil.

Diferente é a situação dos brasileiros e brasileiras mais integrados à cultura e sociedade estadunidenses e, sobretudo, das segundas gerações que já não compartilham com os pais o sonho do retorno ou as dificuldades da integração. Nestes casos, a participação em grupos religiosos, sociais e culturais deixa de ser uma necessidade e, eventualmente, pode se tornar uma opção axiologicamente determinada.

Seja como for, o crescimento das associações brasileiras, como afirma Pinheiro de Souza, representa um amadurecimento das comunidades e contribuem para a formação e o fortalecimento de uma consciência comunitária e organizada, inclusive promovendo e realizando

\footnotetext{
${ }^{28}$ MARTES, Ana Cristina Braga. Os imigrantes brasileiros e as Igrejas em Massachusetts. In: REIS, Rossana Rocha e SALES, Teresa (orgs). Cenas do Brasil migrante, p. 93.
} 
uma amostra do tipo de sociedade pela qual lutam: "negam-se a dividir a comunidade entre legais e ilegais e se recusam a culpar os imigrantes como responsáveis pelo endurecimento das leis de imigração, um pregão comum do grupo anti-imigrante". ${ }^{29}$

\subsection{Emigração em busca da plena cidadania}

Ao que tudo indica, a vida dos brasileiros nos Estados Unidos é focalizada pela luta pela plena cidadania. Entendemos por cidadania, aqui, não apenas o direito de usufruir certas prerrogativas inerentes à condição humana previamente determinadas e garantidas pelo Estado, mas, antes, o direito tanto de ser reconhecido como sujeito de direitos, quanto de suscitá-los. Em outras palavras, ultrapassa-se a idéia de cidadania passiva, como concessão que o Estado faz de ser incluído no sistema vigente, para assumir a cidadania ativa, na qual o migrante, além de usufruir os direitos fundamentais, torna-se também partícipe da própria definição de novos direitos e partícipe do processo de transformação da sociedade em que vive.

Esta noção de cidadania evita o risco de compreender a luta dos emigrantes como mera busca individual de determinadas garantias legais do Estado de chegada (por exemplo, documentação, serviços sanitários etc.), exigindo, ao contrário, o acesso a espaços sociais e políticos de definição e construção de uma nova sociedade e de uma cidadania universal. Ser cidadão, pois, significa ter direito de ser incluído e, ao mesmo tempo, ocupar espaços públicos para participar da transformação do sistema vigente.

Em princípio, a plena cidadania parece ser uma quimera para a comunidade brasileira que é constituída, em boa parte, por migrantes em situação irregular e, por isso, potencialmente em constante risco de deportação. Em geral, nestas condições, a regra básica de sobrevivência é permanecer escondido, “invisível”. É evidente que qualquer tipo de luta reivindicativa de direitos gera visibilidade, sobretudo, quando a reivindicação está acompanhada por alguma forma de conflito de interesses.

Além disso, a busca pela plena cidadania pressupõe, comumente, a articulação de um grande número de pessoas em vista da formação de grupos de pressão que tenham real poder de interlocução. Isso implica a superação do individualismo e, ao mesmo tempo, a formação ou fortalecimento de um espírito social, solidário e comunitário que está na base dos grupos

\footnotetext{
${ }^{29}$ SOUZA, Heloisa Maria Galvão Pinheiro de. Associações brasileiras em Boston. Um primeiro olhar. In: Travessia, ano XII, n. 34 (maio-agosto/99) 33.
} 
políticos. Em outras palavras, muitos brasileiros emigram para melhorar as próprias condições de vida, lutam para conseguir o dinheiro suficiente para voltar ao Brasil e, portanto, não estão muito interessados na promoção dos direitos dos migrantes ou da comunidade brasileira no país norteamericano. Finalmente, não podem ser menosprezadas as dificuldades relacionadas à desconfiança e, até, preconceito em relação ao mundo da política.

No entanto, apesar de todas essas dificuldades, não há dúvida de que há um significativo grupo de brasileiros e brasileiras - principalmente aqueles que decidiram permanecer nos EUA que estão começando a se defrontar com sérias dificuldades cuja solução pode ser alcançada apenas por meio da mobilização coletiva.

Um exemplo é ilustrado por Sales e Loureiro ${ }^{30}$ que descrevem, de forma detalhada, a luta da comunidade brasileira de Massachusetts pelo acesso dos filhos dos migrantes irregulares à universidade. Assim, apesar da hostilidade de segmentos da sociedade norte-americana que vêem nessa concessão "um incentivo adicional à emigração irregular, uma recompensa aos que desobedeceram as leis norte-americanas e um encargo injusto sobre o contribuinte", fortaleceu-se uma mobilização de atores sociais pelos direitos dos estudantes indocumentados, inclusive com o envolvimento das lideranças comunitárias brasileiras. Segundo as pesquisadoras,

As lideranças comunitárias vêm dando mostra de crescente amadurecimento, pois se revelaram capazes de, vencendo discordâncias e até mesmo animosidades que anteriormente as caracterizavam, trabalhar de forma concertada em prol de um objetivo de grande interesse para a comunidade como um todo. A questão ilustra também a importância de que a comunidade brasileira rompa o isolamento que ainda a caracteriza e busque aproximar-se de outras comunidades imigrantes mais tradicionais nos Estados Unidos, como a hispânica e a asiática, com as quais muito pode ser aprendido sobre estratégias de mobilização, principalmente no âmbito legislativo. ${ }^{31}$

A luta política envolve reivindicações comuns entre migrantes irregulares de várias nacionalidades, o que implica o fim do isolamento e a busca de uma maior articulação e interação entre os diferentes grupos "étnicos". Há, no entanto, também a procura de espaços específicos para a comunidade brasileira no interior das mais numerosas, antigas e influentes comunidades asiáticas e hispânicas que, não raramente, acabam assimilando ou incorporando a

\footnotetext{
${ }^{30}$ Cf. SALES e LOUREIRO, op. cit., p. 231-238.

${ }^{31}$ Ibidem, p. 237.
} 
brasileira com sua identidade e especificidade..$^{32}$ É esse um outro grande desafio da mobilização política dos brasileiros nos EUA.

Finalmente, cabe sinalizar o importante papel que as associações religiosas podem desempenhar para o fortalecimento da mobilização sócio-política das comunidades brasileiras nos EUA. Isso, no entanto, implica na superação de um atendimento pastoral direcionado meramente à assistência individual dos problemas imediatos dos migrantes ${ }^{33}$, para a assunção de uma ótica coletiva e estrutural em vista da construção de uma sociedade mais humana e inclusiva. Nesta ótica a "missão é percebida como algo que vai mais além de ser uma comunidade que acolhe e apóia os migrantes brasileiros: sua presença nos EUA poderia significar 'um celeiro de expansão da libertação', ao trazer uma contribuição própria a partir da experiência que vem se realizando atualmente no Brasil". ${ }^{34}$

\section{Conclusão}

A emigração brasileira para os Estados Unidos representa um sinal da dificuldade que o Brasil tem de satisfazer as necessidades e desejos de seus cidadãos e, ao mesmo tempo, um testemunho da coragem de brasileiros e brasileiras que enfrentam todo tipo de desafio em busca da realização de seus sonhos. No entanto, cabe realçar que, assim como no Brasil, a vida nos EUA permanece caracterizada pela luta: a luta pela sobrevivência, pelo trabalho digno, pelos direitos políticos e civis, pelo reconhecimento da própria dignidade e diversidade, pela libertação da opressão de atravessadores ou empregadores, enfim, pelo direito de se sentir e ser tratado como ser humano.

\section{BIBLIOGRAFIA}

COMISIÓN ECONÓMICA PARA AMÉRICA LATINA Y EL CARIBE. Panorama Social de América Latina 2004. Disponível em http://www.eclac.cl Acesso em: 10 de agosto de 2005

\footnotetext{
${ }^{32}$ Cf. RIBEIRO, Gustavo Lins. O que faz o Brasil, Brazil. In: REIS, Rossana Rocha e SALES, Teresa (orgs). Cenas do Brasil migrante, p. 64.

${ }^{33}$ MARTES, op. cit., p. 93.

${ }^{34}$ RIBEIRO, Lúcia. Práticas religiosas. Sua importância no cotidiano do migrante. In: SERVIÇO PASTORAL AO MIGRANTE (org.). Travessia na de\$ordem global. Fórum Social das Migrações, p. 266.
} 
FUSCO, Wilson. "Redes sociais nas migrações entre Governador Valadares e os Estados Unidos”. In: CNPD (org.), Migrações internacionais - contribuições para políticas. Brasília, CNPD, 2001, p. 427-446.

IOM. World Migration Report - 2005. Costs and benefits of international migration. Vol. 3. Disponível em: http://www.iom.int

MARINUCCI, Roberto. A Pastoral dos Brasileiros no Exterior (PBE - CNBB). In: SERVIÇO PASTORAL DOS MIGRANTES (org.). Travessia na de\$ordem global. Fórum Social das Migrações. São Paulo: Paulinas, 2005, p. 253-260

MARTES, Ana Cristina Braga. Os imigrantes brasileiros e as Igrejas em Massachusetts. In: REIS, Rossana Rocha e SALES, Teresa (orgs). Cenas do Brasil migrante. São Paulo: Jinkings, 1999, p. 87-122.

MEIHY, José Carlos Sebe Bom. Brasil fora de si-experiências de brasileiros em Nova York. São Paulo: Parábola, 2004.

MORELL BLANCH, Antonio. El papel de las asociaciones de inmigrantes en la sociedad de acogida. In: Migraciones 17 (junio 2005) 111-142.

ONU - DEPARTMENT OF ECONOMIC AND SOCIAL AFFAIRS. World Economic and Social Survey - 2004. Disponível em : http://www.un.org/esa/analysis/wess/ Acesso em: 10 de maio de 2005.

RIBEIRO, Gustavo Lins. O que faz o Brasil, Brazil. In: REIS, Rossana Rocha e SALES, Teresa (orgs). Cenas do Brasil migrante. São Paulo: Jinkings, 1999.

RIBEIRO, Lúcia. Práticas religiosas. Sua importância no cotidiano do migrante. In: SERVIÇO PASTORAL AO MIGRANTE (org.). Travessia na de\$ordem global. Fórum Social das Migrações. São Paulo, Paulinas, 2005, p. 261-266.

SALES, Teresa. Brasileiros longe de casa. São Paulo: Cortez, 1999. . "Segunda geração de emigrantes brasileiros nos EUA". In: CNPD (org.), Migrações internacionais - contribuições para políticas. Brasília, CNPD, 2001, p. 361-374. 
SALES, Teresa e LOUREIRO, Márcia. Imigrantes brasileiros adolescentes e de segunda geração em Massachusetts, EUA. In: Revista Brasileira de Estudos de População. Campinas, v. 21, n. 2, p. 217-239, jul./dez. 2004.

SASSEN, Saskia. Globalizzati e scontenti. Il destino delle minoranze nel nuovo ordine mondiale. Milano: Il Saggiatore, 2002.

SERRANO, Javier O. Acerca de las remesas de dinero que envían los migrantes: procesos de intercambio social em contextos migratórios internacionales. In: Estudios Migratorios Latinoamericanos, XVII, n. 51, agosto 2003, pp. 307-33

SOUZA, Heloisa Maria Galvão Pinheiro de. Associações brasileiras em Boston. Um primeiro olhar. In: Travessia, ano XII, nº 34 (maio-agosto/99) 29-33. 